\title{
A blended collaborative writing approach for Chinese L2 primary school students
}

\author{
Lung-Hsiang Wong, Wenli Chen, Ching-Sing Chai \\ Nanyang Technological University \\ Chee-Kuen Chin \\ Singapore Centre for Chinese Language \\ Ping Gao \\ University of Northern Iowa
}

\begin{abstract}
This paper outlines an adaptable collaborative writing approach employing a wiki to address the typical weaknesses of young Singaporean Chinese students learning Chinese as second language (L2) in Chinese writing. These students' problems in writing include limited and incorrect use of vocabulary, English-style grammar, badly structured passages, and so on. The collaborative writing approach, V.S.P.O.W., can be characterised as a recursive, bottom-up writing process that requires the students to collaboratively carry out wiki-based "word/phrase pooling" (V), "sentence making" $(\mathrm{S})$, "paragraph writing" $(\mathrm{P})$, and "outlining" $(\mathrm{O})$; and eventually individual essay writing (W). We analysed the potential learning effects of the writing process among Primary 4 (10-year-old) students - especially in addressing and leveraging students' individual differences. Through teacher and student-initiated customisation of the original V.S.P.O.W. process, we hope to improve the students' micro-skills for writing. The results of the pilot study show that the target students' micro-skills for writing were significantly improved, which could be attributed to emerging peer coaching practices among them.
\end{abstract}

\section{Introduction}

Writing is a highly complex process, comprised of various sub-processes that occur not one after another in a strict linear sequence, but cyclically and in varying patterns. Instead of concentrating on the writing that students produced and making critical comments on it, teachers could aim to help students write better by aiding them in the process of writing. This is especially crucial for young second language (L2) learners who typically lack adequate writing micro-skills such as the correct use of punctuation marks, vocabulary, grammar, essay structures, etc., to tackle cognitively demanding writing tasks. Take typical Singapore students who are educated in an education system that favours English language (People's Daily Online, 2005) for an example, they always find it a challenge to learn Chinese (Wong, Boticki, Sun \& Looi, 2011), especially in acquiring writing skills (Liang, 2000; Sim, 2005; Wong, Chai \& Gao, 2011).

In this paper, we report the design and the pilot study of a wiki-based collaborative Chinese essay writing approach aiming to address the weaknesses of primary school students in L2 writing. These problems include limited and incorrect use of vocabulary, English-style grammar, poor essay structure, and so on. The highly 
adaptable collaborative writing approach can be characterised as a recursive, bottom-up process that enables the students to collaboratively carry out "word/phrase pooling" (vocabulary), "sentence making", "paragraph writing" and "outlining" on their group wiki pages (which are student-generated intermediate writing resources); and eventually composing their essays individually ("essay writing") with word processing software. By adaptable we mean that learning approach and learning path (in the case of the reported approach, these terms refer to the ways intermediate writing resources were used and the writing process) are adjustable by both teachers and students. We name the process as V.S.P.O.W. (Vocabulary, Sentence, Paragraph, Outlines, Writing).

This paper focuses on a conceptual analysis of the design of V.S.P.O.W. with support from the preliminary findings of a pilot study conducted at a Primary 4 (10-year-old) Chinese L2 class in Nan Chiau Primary School, Singapore. We also analyse the potential learning effects of V.S.P.O.W. for L2 students in terms of how it could address and even leverage students' individual differences through teacher or studentinitiated customisation of the writing process, and emerging peer coaching to improve the students' micro-skills for writing.

\section{Literature review}

\section{L2 writing instruction: From traditional, product-oriented pedagogy to process writing}

Writing is arguably the most complex skill in language learning. Traditional writing pedagogy focuses on writing product (He, 2005). As Silva (1990) and Ferris and Hedgcock (1998) stated, in early L2 writing instruction, a writing task was the "controlled composition" designed to give students practice with particular syntactic patterns and/or lexical forms. Following this model, students are expected to generate connected discourse by combining and arranging sentences into paragraphs based on prescribed formulas. Process pedagogy arose in the late 1960s in reaction to the dominance of product-centred pedagogy (Matsuda, 2003). This approach views writing as an ongoing process in which students follow a given set of procedures for planning, drafting, revising, editing, and publishing their writing (NDE, n.d.). It places a greater interest upon peer review, audience, purpose, and author's voice (Atkinson, 2003; Williams, 2005).

Although process writing was considered the most successful approach in the history of pedagogical reform in the teaching of writing (Matsuda, 2003), it is not without limitations. As an approach that was originally developed for L1 students, early descriptions of process writing advocated teaching novices the cognitive strategies used by expert writers (Flower \& Hayes, 1977; Flower, 1979). L2 students, however, might suffer from "language threshold" , a hypothesis which suggests that learners must have sufficient L2 competence in order to tap into their L1 writing skills (Grabe, 2003; Williams, 2005). Their low proficiency in the target language often results in their greater attention to the lower-level forms of micro-writing skills such as transcription or production of written text, vocabulary and grammar (e.g., Silva, 1993). The higher level, content related tasks such as planning (e.g., Yau, 1989) and reviewing (e.g., Silva, 1990) are often neglected. The language barrier thus poses serious challenges for L2 students seeking to practise more advanced and cognitively demanding writing strategies. 
In this regard, some scholars (Atkinson, 2003; Matsuda, 2003; Murray \& Hourigan, 2008) have proposed applying "post-process" approaches to L2 writing, which are not intended to replace process pedagogy but rather to expand and broaden the approach. In essence, a post-process writing perspective shifts the focus from cognitive to interactive and social writing processes, where the stages of writing need not follow a fixed sequence. Likewise, Hinkel (2006) observed that many teachers and researchers have advocated the integration of grammar and vocabulary with L2 writing instruction, to better enable writers to communicate meaningfully and appropriately. She noted how L2 writing pedagogy is putting more emphasis on the need to integrate bottom-up and top-down skills. This corresponds with the current trend for teaching integrated skills (Chetty, 2006).

\section{Web 2.0 technology and wiki for collaborative writing}

Contemporary models of writing instruction have been showing an increasing emphasis on personal voice, writers' interactions with their community, and collaborative writing. Such a trend matches the three essential characteristics of the Web 2.0 technology, namely, personalisation, interactivity and collaborative content building (Millard \& Ross, 2006). Web 2.0 offers affordances that can be designed as learning environments, enabling writers to become part of an active learning community (Alm, 2006; Franklin \& Van Harmelen, 2007).

In particular, Alm-Lequeux (2004) related to the self-determination theory (SDT) in explaining how online, especially Web 2.0-based, language learning environments may increase the students' learning motivation. Self-determination theory is based on the assumption that all humans share the three major psychological needs of "relatedness" (to have a sense of belongingness both with other individuals and with the community), "competence" (to feel effective in one's ongoing interaction with the social environment - that leads people to seek challenges that are optimal for their capacities) and "autonomy" (to be the perceived origin or source of one's own behaviour). The relevance of these needs is recognised in educational and language learning theories, that is, Vygotsky's (1978) social learning theory (most people learn better in a social context), Krashen's (1985) concept of "input +1 " (providing instructions just above the learner's present state of knowledge), and autonomous learning (e.g., Holec, 1979), among others. These three learning theories imply the necessity of adaptable learning processes as the traditional "one-size-fits-all" instructional designs are not appropriate for the open-endedness of the learning approaches as advocated by the theories.

As a prevailing Web 2.0 tool, wikis similarly have potential for motivating student learning. Franklin and Van Harmelen (2007) define a wiki as "a system that allows one or more people to build up a corpus of knowledge in a set of interlinked web pages, using a process of creating and editing pages" (p.5). Wikis provide a solid ground on social interaction and collaboration (Godwin-Jones, 2003), which are the means to motivate the students to seek outcomes beneficial to themselves and their peers instead of competing against each other (De Pedro et al., 2006; Wheeler, Yeomans \& Wheeler, 2008).

Wikis open up the possibility for the design of innovative collaborative writing approaches (e.g., Bradley, Lindström \& Rystedt, 2010; Kessler, 2009; Mak \& Coniam, 2008). Nevertheless, like process writing, wikis are not without limitations. Over the recent years, various scholars have pointed out general or context-specific drawbacks 
of applying wikis for learning, such as students' reluctance to allow others to see their unfinished documents (De Pedro et al, 2006) and to revise each others' work (Wheeler \& Wheeler, 2007); students' tendencies towards only contributing intensively to the wiki documents in-class, whilst merely reading them when out of class (Wheeler et al., 2008); students' preference for publishing only the finished product (Zorko, 2009); and unmotivated student use of the technology due to poorly designed and supported teaching formats (Cole, 2009).

In short, we aim to explore new approaches to address Chinese (or any other language) L2 students' fundamental needs to overcome the "language threshold" before they proceed to learn advanced writing skills. Could collaborative writing be a plausible answer to our inquiry? Can Web 2.0 technology offer the affordances needed for such activities, while avoiding the pitfalls of product-oriented writing pedagogy? Is blended face to face and asynchronous collaborative writing an effective approach in achieving the stated goal?

\section{Study description}

This study commenced in January 2008 and involved three researchers from the National Institute of Education and four Chinese language teachers from Nan Chiau Primary School with the aim of co-designing a pedagogical approach to address students' challenges in Chinese writing (e.g., limited vocabulary, English-style grammar). The co-design activities were conducted in the form of collaborative inquiry (Bray, 2002; Darling-Hammond, 1996), a systematic approach that promotes collaboration between researchers and teachers to engage in active learning for the advancement of both knowledge and practice (Batliwala, 2003; Wong, Gao, Chai \& Chin, 2011). After the initial design of V.S.P.O.W. was in place, we conducted rounds of formative experiments as proposed by the design research approach (Brown, 1992) to evaluate and refine the approach as a "point-at-able" model. The first pilot study was conducted by one of the teachers in her Primary 4 class with consent from the parents of the eighteen participating students.

\section{Learning design}

As shown in Figure 1, V.S.P.O.W. can be characterised as a blended, bottom-up composition writing process that encompasses collaborative and independent writing, synchronous (face to face) and asynchronous (online) collaborations, and in-school and out-of-school activities. The process designed is intended to offer flexibility for teachers to customise and execute it for several rounds on the same group of students. Currently, V.S.P.O.W. is meant for pictorial compositions.

The writing process consists of five major stages, namely, word/phrase pooling, sentence making, paragraph writing, outlining, and essay writing. Each of the first three stages is subdivided into three similar steps, namely, intra-group collaborative "pre-writing" (i.e., word/phrase pooling, sentence making, or paragraph writing), intra-group and inter-group reviews, and class-wide selections.

We use the word/phrase pooling stage to elaborate on how the three steps are executed. The stage begins with students working in face to face groups sharing one computer to brainstorm words/phrases that describe the scenario or the story in the given picture(s). They take turn to input their personal contributions to their group 
wiki page. Subsequently, the students log on to the wiki site from home to edit their group word lists. They could also browse and learn from other group lists, spot and correct mistakes (with a different font colour, i.e., the red colour), and place a question mark next to each of the words/phrases that they do not understand. The question marks serve as requests to the contributors to add explanations on the wiki pages. In addition, the wiki's multi-page feature facilitates neat organisation of various groups' work and inter-group reviews and referencing. Henceforth, the wiki affordances of asynchronous multi-user editing and commentary are well-exploited during such a dynamic collaborative writing process. Finally, the teacher facilitates a class-wide discussion to select a set of words/phrases from all the group lists. The selected word list is then "fed" into the next stage as a reference for the groups to proceed to make sentences.

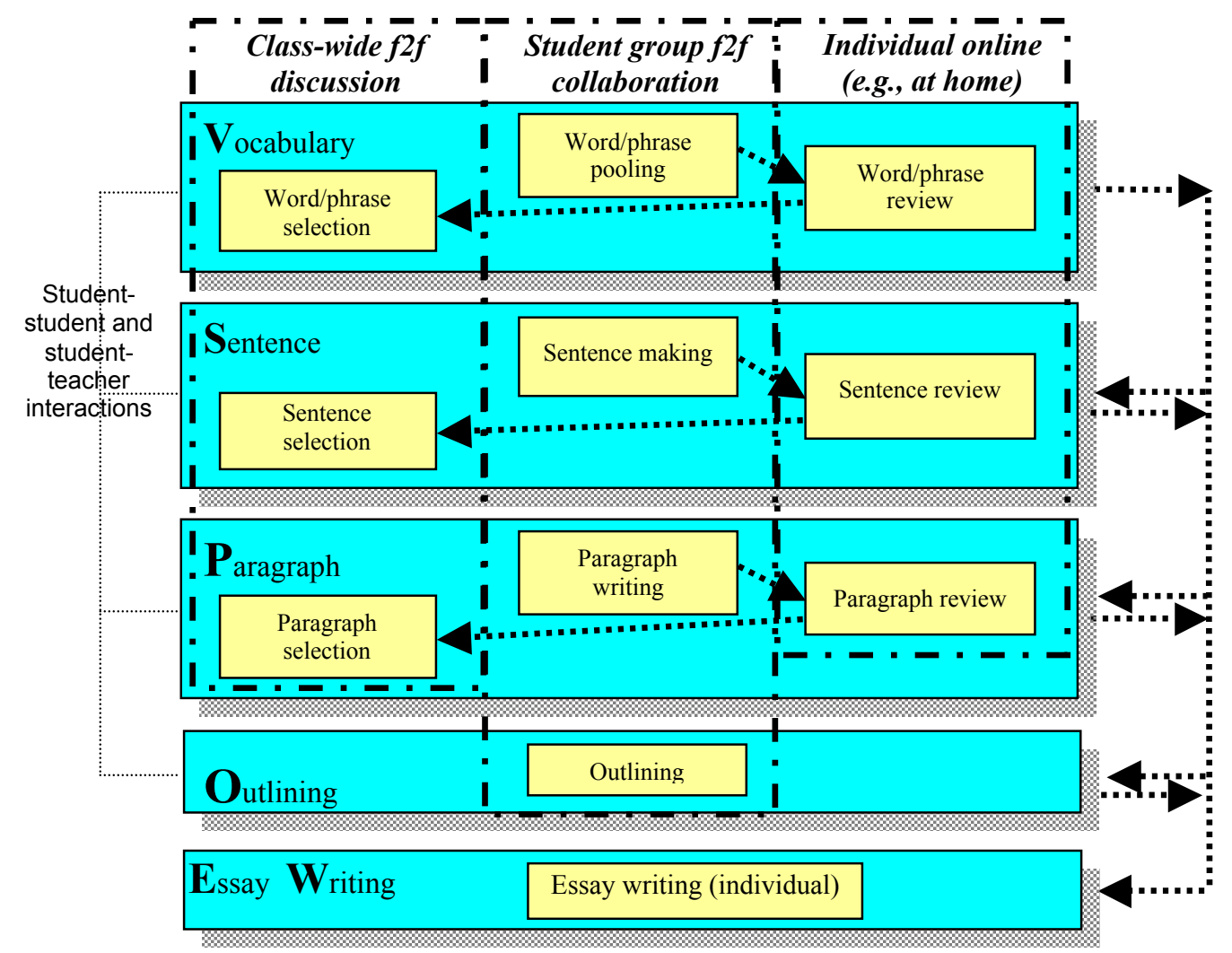

Figure 1: The V.S.P.O.W. process

A similar three-step process is repeated in the sentence making and paragraph writing stages, all making use of the same group wiki pages (see Figure 2 for a sample screen capture of a group wiki page for the first three stages of activities). The last two stages involve a single step each - collaborative outlining and individual essay writing.

The entire process is highly adaptable in the sense that students need not go through every single stage or sub-step - as indicated by the dashed arrows in Figure 1. Depending on the students' language ability, the teacher (or the students themselves) 
may choose to skip any combination of the stages or sub-steps. For example, high ability students may not bother to go through word/phrase pooling or sentence making before they proceed to write paragraphs.

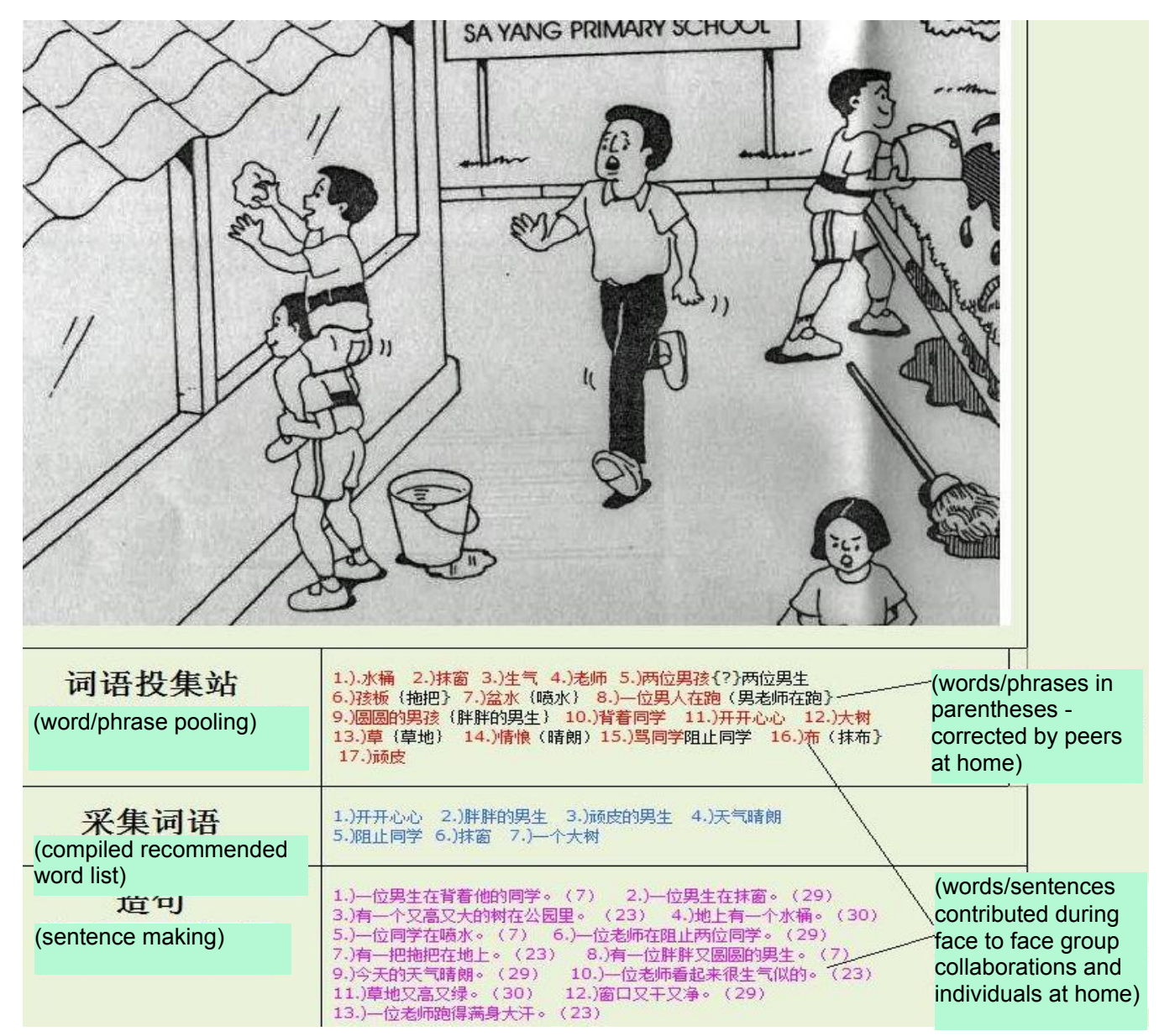

Figure 2: Screen capture of a group wiki page

In addition, as teachers may iteratively execute rounds of V.S.P.O.W., they could opt to execute partial cycles in early rounds for weaker students. For example, the process could be concluded at the sentence making stage in round 1 , at the paragraph writing stage in round 2; and complete cycles from round 3 onwards. Therefore, instead of being "intimidated" by the requirement of producing complete essays in early rounds, students could take their time to build up lower level writing skills.

Based on the same principle, we envisage V.S.P.O.W. to be applied to students at lower primary levels with varied baseline writing skills specified by the standard curriculum, say, Primary 1 and Primary 3 students who need to pick up sentence making and paragraph writing skills respectively (thus carrying out "V.S." and "V.S.P." respectively). 


\section{Pilot study: Customisation of the writing process}

The pilot study in the class of 18 students took place in March-September 2008. In the spirit of teacher empowerment, we advised the teacher to make her own decision on customising V.S.P.O.W., while we assumed the role of consultant. The teacher executed four rounds of V.S.P.O.W. The students worked in the same group (four groups altogether) as their regular Chinese class, which were all heterogeneous (mixed ability in Chinese proficiency) groups.

- Round 1 (March-April): The teacher supplied an image file that depicted a scenario of spring cleaning in a school compound. The image was split into four zones of equal size, with each zone being assigned to one group for collaborative word/phrase pooling. All groups then referred to the entire image for sentence making. This round was concluded at the sentence making stage, i.e., the process can be coded as "V.S."

- Round 2 (May-June): In order to bring authenticity to the activity, the teacher facilitated the taking of school sports day photos by the students. The class discussed and selected one of the photos taken at a track competition. All groups worked on the photo from the beginning in word/phrase pooling, sentence making, and finally paragraph writing, i.e., "V.S.P."

- Round 3 (July-August): The teacher assigned each group an area in the school compound (e.g., the canteen, the garden, etc.), and instructed them to take a photo during recess of the designated areas. The group then worked on the photo that they took for sentence making (they skipped word/ phrase pooling). Subsequently, each group selected any three out of the four photos and collaboratively wrote a paragraph on each selected photo. They then collaboratively prepared the outlines, and eventually wrote their essays individually, i.e., "S.P.O.W."

- Round 4 (August-September): The teacher facilitated the class to make up a story about a classmate getting caught cheating during a quiz. The class then enacted the story and took four photos. This time round, the teacher instructed the students to try out a hybrid collaborative "outlining-sentence making" approach on each photo, followed by collaborative paragraph writing and individual essay writing, i.e., "O+S.P.W."

The time interval between two adjacent face to face sessions (e.g., between intra-group word/phrase pooling and class-wide selection of the word list) was typically one week, giving students some time to log on to wiki from home for individual reviews.

\section{Pilot study: Data collection and evaluation}

To evaluate the impact of the four-round implementation of V.S.P.O.W., we executed a data collection and analysis plan to measure the changes of the following aspects before and after the study, (1) students' various micro-skills for Chinese writing; and (2) students' perceptions. The plan consisted of five components as described below.

First, we made use of two pictorial compositions written by individual students during routine classroom sessions with paper and pen as the basis of the pre- and post-tests. The contents of the pictures given to the students in both tests were not related to the 
contents of the pictures given to or the photos generated by the students for their four rounds of V.S.P.O.W. processes. The essays were written two weeks before the beginning and a week after the end of the study respectively. Two teachers marked the essays independently according to a rubric that we co-developed. The rubric consists of 9 items: punctuation marks, characters (correctness), vocabulary (richness), vocabulary (accuracy), sentence and grammar, structure, organization, content (richness), and content (analytical skill). Each item was graded on a scale of 1-5. The Pearson $r$ values for all items range from .74 to .91, which indicate good inter-rater reliability. Paired-sample $t$ tests were then employed to examine whether there were improvements in students' micro-skills in essay writing.

Second, we administered pre-intervention and post-intervention surveys to measure the students' perceptions and attitudes towards learning Chinese, Chinese essay writing, and technology for learning. All the students were asked to respond to questions on a Likert scale of four ( 1 = strongly agree, $2=$ agree, $3=$ disagree, and $4=$ strong disagree). Paired-samples $t$ tests were employed to examine whether there were changes in student perceptions. A few items were appended to the post-survey to find out students' perceptions towards the wiki-based collaborative writing; the results of which were examined by descriptive analysis.

Third, we invited three students of high, medium and low ability in Chinese language (according to their academic results) respectively from the class for one to one, semistructured pre- and post-interviews. The intention was to find out more about the students' perceptions and experience of the collaborative writing activities. Pseudonyms are used here to protect the identities of the interviewees, namely, Haiqing (high ability, female), Mingzhe (medium ability, male), and Liguo (low ability, male). They belonged to three different student groups in the activities.

Fourth, we analysed the wiki page history to uncover students' learning and peer coaching process. According to the design, peer coaching may take place in two forms: (1) in class, face to face, small-group (pre-)writing; and (2) out of class, asynchronous, personal wiki editing. Due to the time and resource constraints, we did not track the face to face discussion. We managed to gain some preliminary understanding about the face to face discussion through post-interviews and the post-questionnaire. For the out of class wiki editing, we adopted the "code and count" approach to categorise and work out the descriptive statistics of the edits that the students made on the wiki pages.

Fifth, our face to face and email interactions with the teacher throughout the study were also documented as they often contained the teacher's first hand observation and reflection on the design and the pilot study. Such data was treated as secondary evidences for triangulating the first four sets of data.

\section{Findings}

\section{Improvement of students' micro-skills in Chinese writing and attitudes}

Table 1 shows the results of the paired-sample $t$-tests applied to compare the students' performances on the nine assessed micro-skills in the pre- and post-tests. 
Table 1: Paired-sample $t$-tests between pre-test and post-test $(\mathrm{N}=18)$

\begin{tabular}{|c|c|c|c|c|c|}
\hline & & Mean & SD & $\begin{array}{c}\text { Mean } \\
\text { difference }\end{array}$ & $t$ \\
\hline \multirow[t]{2}{*}{ Punctuation marks } & Pre-test & 3.6 & .78 & \multirow[t]{2}{*}{-.72} & \multirow[t]{2}{*}{$-4.58^{* * *}$} \\
\hline & Post-test & 4.3 & .49 & & \\
\hline \multirow[t]{2}{*}{ Characters } & Pre-test & 2.5 & .79 & \multirow[t]{2}{*}{-1.67} & \multirow[t]{2}{*}{$-11.90^{\star \star \star}$} \\
\hline & Post-test & 4.2 & .51 & & \\
\hline \multirow[t]{2}{*}{ Words - richness } & Pre-test & 2.6 & .70 & \multirow[t]{2}{*}{-1.78} & \multirow[t]{2}{*}{$-13.76^{\star * *}$} \\
\hline & Post-test & 4.4 & .50 & & \\
\hline \multirow[t]{2}{*}{ Words - accuracy } & Pre-test & 2.7 & .75 & \multirow[t]{2}{*}{-1.33} & \multirow{2}{*}{$-8.25^{\star \star \star}$} \\
\hline & Post-test & 4.1 & .54 & & \\
\hline \multirow[t]{2}{*}{ Sentences } & Pre-test & 2.7 & .90 & \multirow[t]{2}{*}{-1.44} & \multirow[t]{2}{*}{$-9.95^{\star \star \star}$} \\
\hline & Post-test & 4.2 & .62 & & \\
\hline \multirow[t]{2}{*}{ Organisation } & Pre-test & 2.9 & .73 & \multirow[t]{2}{*}{-1.22} & \multirow[t]{2}{*}{$-12.12^{* * *}$} \\
\hline & Post-test & 4.2 & .62 & & \\
\hline \multirow[t]{2}{*}{ Structure } & Pre-test & 2.8 & .71 & \multirow[t]{2}{*}{-1.50} & \multirow[t]{2}{*}{$-9.00^{\star \star \star}$} \\
\hline & Post-test & 4.3 & .60 & & \\
\hline \multirow[t]{2}{*}{ Content - richness } & Pre-test & 2.6 & .62 & \multirow[t]{2}{*}{-2.00} & \multirow[t]{2}{*}{$-14.28^{\star * *}$} \\
\hline & Post-test & 4.6 & .51 & & \\
\hline \multirow[t]{2}{*}{ Content - analysis } & Pre-test & 2.4 & .60 & \multirow[t]{2}{*}{-2.17} & \multirow[t]{2}{*}{$-17.87^{\star \star \star}$} \\
\hline & Post-test & 4.6 & .51 & & \\
\hline
\end{tabular}

We admit that the sample size of 18 is relatively small for conducting a $t$-test. Nevertheless, the results still show that the students have achieved significant improvement in every assessed micro-skill for writing after the intervention. As the pre-tests and post-tests were paper and pen-based individual essays while the intervention was ICT-mediated collaborative writing, the results probably imply a successful transfer of the micro-skills for writing that the students have improved through the intervention across the two different mediums and approaches of writing. In addition, the standard deviations (SD) of all items were dropped, indicating that the differences among the students in their writing skills had decreased.

We have also performed descriptive analysis on the students' self-reported areas of improvements via the post-survey. We found that majority of the students agreed or strongly agreed that the 4-round intervention had resulted in their significant improvements in: Chinese text input speed $(88.9 \%)$, richness of vocabulary used in their essays $(83.3 \%)$, sentence making skills $(88.9 \%)$, the "excitement" of their essay content $(88.9 \%)$, and visual observation skills $(100 \%)$.

Furthermore, we conducted paired-samples $t$-test to examine whether there were significant changes in students' perceptions toward Chinese learning, Chinese composition and technology for learning. The results show significantly positive changes in the students' perceptions in the "beauty" of Chinese $(p<.001)$, their abilities in writing Chinese compositions without looking at pictures $(p<.01)$ and their attitudes toward the user friendliness of computer software $(p<.05)$. For the rest of the items, the students held more positive attitudes as well, although the changes were not significant. We believe that it was because the intervention was relatively short.

We have also performed descriptive analysis on the students' responses to the postsurvey questions pertaining to their attitudes toward the intervention. This yielded positive results. For example, $94.4 \%$ of the pilot students agreed or strongly agreed that "I enjoyed the wiki-based group composition activities"; 83.3\% agreed or strongly 
agreed that "I wish I could participate in more rounds of wiki-based group composition activities"; $94.4 \%$ agreed or strongly agreed that the intervention "will help me in writing better compositions in the future."

\section{Students' collaborative (stage 1-4) writing process}

The post-survey results show that the students were keen on helping each other during the writing activities. All participants agreed or strongly agreed that "I liked to help my classmates during the wiki-based group composition activities." $66.7 \%$ of them agreed or strongly agreed that "I preferred my classmates than my teacher to help me during the wiki-based group composition activities."

To find out how the students collaborate during the small group sessions, we asked the interviewees the following questions, "Do you think you have helped your group mates more or the other way round? In what areas have you offered help to others and others have helped you?" Haiqing, the high ability interviewee, surprised us that she perceived herself as receiving more help than helping others. This contradicts with our commonsense expectation that the "best" students usually dominate their learning groups. She claimed that she helped her group mates in her strongest aspect - she was the fastest in Chinese computer input. Conversely, she was weaker in sentence composing and was grateful to her group mates' help. Her teacher confirmed this and observed her vast improvement in this area since the study began. Medium ability Mingzhe believed he and his teammates had helped each other equally. They helped by verifying each other's contributions. The greatest help that he offered to the group was Chinese input while he gained help mainly in vocabulary and sentence making. Finally, low ability Liguo was not sure if he had helped his team mates more or the other way round. However, he proclaimed, perhaps both proudly and displeasedly, "They (teammates) came up with the points (outlines). I then filled in with the complete story. They needed a little imagination but I needed a lot." Nevertheless, he was pleased to have learnt new vocabulary from his teammates.

We have also made use of the post questionnaire to find out the areas for which individual students perceived that they had offered or received the greatest help in their groups. We compiled two groups' responses to these questions in Table 2 as an illustration. Note that we separated Chinese computer input and pinyin, a scheme of Romanising Chinese characters based on their pronunciations, which is also the Chinese character input method that the students had been using, as two distinguished items. There were students who were good in pinyin (i.e., to figure out the correct pinyin of each Chinese character) but weak in Chinese computer input (a kinaesthetic skill), or vice-versa. For instance, Haiqing, the high ability interviewee, indicated during the post-interview that she was a fast Chinese computer typist but often needed her teammates to correct her pinyin.

Table 2: Examples of how students helped each other within their groups

\begin{tabular}{|l|l|l|l|l|l|}
\hline \multicolumn{3}{|c|}{ Group A } & \multicolumn{3}{c|}{ Group E } \\
\hline Student & $\begin{array}{c}\text { Offered greatest } \\
\text { help in }\end{array}$ & $\begin{array}{c}\text { Helped most by } \\
\text { teammates in }\end{array}$ & Student & $\begin{array}{c}\text { Offered greatest } \\
\text { help in }\end{array}$ & $\begin{array}{l}\text { Helped most by } \\
\text { teammates in }\end{array}$ \\
\hline Student A & words / phrases & outlines & Student E & pinyin & content/story \\
\hline Student B & Chinese input & Chinese input & Student F & pinyin & pinyin \\
\hline Student C & pinyin & pinyin & Student G & sentence making & pinyin \\
\hline Student D & words / phrases & Chinese input & Student H & pinyin & pinyin \\
\hline Mingzhe & pinyin & sentence making & Haiqing & Chinese input & sentence making \\
\hline
\end{tabular}


Although the data collected through this means were relatively coarse grained, it did imply that the students within each group had been coaching and complementing each others in different areas. For example, in Group E, Haiqing might have learnt a lot from Student G in sentence making. There were cases where a student perceived that she had offered and received the greatest help in the same area (e.g., Students C, F and $\mathrm{H}$ in pinyin). This probably indicates that most of the teammates were not particularly strong in this particular area but they managed to help each other at different points of time. Furthermore, from Table 2, although pinyin seems to be the aspect for which the students mostly received or offered help, it does not mean that the rest of writing micro-skills were not prominently tackled. Judging by the students' vast improvement in all micro-skills as indicated in Table 1, we argue that the students had offered and received balanced help in these aspects throughout the face to face collaborative sessions.

In addition, we categorised the students' out of class wiki edits at different rounds and stages of the collaborative writing process, and compiled the statistics as shown in Table 3. Non-wiki based activities were excluded in this analysis.

The statistics in Table 4 seem to indicate a relatively low level of out of class wiki editing activities during the four rounds of intervention. This was not surprising as all these activities took place after the in-class small group "pre-writing" sessions. We argue that individual groups' face to face discussions with the advantage of immediate peer feedback would have rectified most of the errors as well as covered most possibilities in pooling vocabulary and sentences during the stages of "V." and "S.". Conversely, the out of class activities were more conducive for students to learn new vocabularies or sentences from other groups, as revealed by all three interviewees who found that it was fun to find out what vocabularies or sentences that other groups had figured out while their group had not.

Table 3: Students' out of class wiki activities

\begin{tabular}{|c|c|c|c|c|c|c|c|c|c|}
\hline Round & Stage & $\begin{array}{l}\text { Request } \\
\text { for } \\
\text { definition } \\
\text { of vocab- } \\
\text { ulary }\end{array}$ & $\begin{array}{l}\text { Contrib- } \\
\text { uting } \\
\text { new } \\
\text { vocab- } \\
\text { ulary }\end{array}$ & $\begin{array}{l}\text { Contrib- } \\
\text { uting } \\
\text { new } \\
\text { sentence }\end{array}$ & $\begin{array}{l}\text { Correct- } \\
\text { ing } \\
\text { punctu- } \\
\text { ation } \\
\text { marks }\end{array}$ & $\begin{array}{l}\text { Correc- } \\
\text { ting } \\
\text { charac- } \\
\text { ters }\end{array}$ & $\begin{array}{c}\text { Correc- } \\
\text { ting voc- } \\
\text { abulary } \\
\text { (accurate } \\
\text { usage) }\end{array}$ & $\begin{array}{l}\text { Correct- } \\
\text { ing } \\
\text { gram- } \\
\text { mar }\end{array}$ & $\begin{array}{l}\text { Modifying } \\
\text { sentence or } \\
\text { paragraph } \\
\text { contents }\end{array}$ \\
\hline \multirow[t]{2}{*}{1} & V & 3 & 6 & -NA- & -NA- & 3 & 3 & -NA- & -NA- \\
\hline & $S$ & 1 & -NA- & 8 & 9 & 4 & 9 & 5 & 5 \\
\hline \multirow[t]{3}{*}{2} & V & 5 & 11 & -NA- & -NA- & 6 & 4 & -NA- & -NA- \\
\hline & $S$ & 0 & -NA- & 7 & 13 & 7 & 10 & 9 & 3 \\
\hline & $\mathrm{P}$ & 1 & -NA- & -NA- & 9 & 3 & 5 & 5 & 1 \\
\hline \multirow[t]{2}{*}{3} & $S$ & 2 & -NA- & 10 & 10 & 4 & 5 & 8 & 6 \\
\hline & $\mathrm{P}$ & 0 & -NA- & -NA- & 11 & 6 & 3 & 6 & 3 \\
\hline \multirow[t]{2}{*}{4} & $\mathrm{O}+\mathrm{S}$ & 0 & -NA- & 4 & 5 & 3 & 0 & 4 & 2 \\
\hline & $\mathrm{P}$ & 0 & -NA- & -NA- & 5 & 5 & 2 & 3 & 0 \\
\hline
\end{tabular}

Given our analysis on all the available data, we argue that intensive peer learning/coaching for individual students had taken place during the in class, face to face, small group (pre-)writing sessions. The value of face to face discussions in the V.S.P.O.W. design, which could hardly be achieved if we instead adopted synchronous writing tools and a 1:1 (one computer per student) setting, is justified. In addition, the out of class, asynchronous, wiki based activities might have served as a supplementary means to enhance students" learning - of course, with the advantages of "self-pacedness" and anytime (if not anywhere) learning. 


\section{Discussion}

\section{Standard process writing versus V.S.P.O.W.}

The V.S.P.O.W. approach was developed with the pragmatic aim of addressing the fundamental linguistic and writing challenges facing younger students in L2 writing. Objective-wise, it seems to be rooted in the traditional rhetoric pedagogy. Yet it does not emphasise writing products as strongly, and neither advocates teacher's direct transfer of linguistic micro-skills and prescribed formulas in writing. Moreover, V.S.P.O.W. reinforces a collaborative writing process. Yet it seems to violate general principles of the "standard" process writing instruction.

Standard process writing requires the students to model after expert writers in writing. Henceforth, the expert writing process is both a means and the end to the students. However, L2 students typically struggle in linguistic related micro-skills which hinder them from carrying out advanced process writing. V.S.P.O.W., conversely, is merely a means to help L2 students in improving their low level writing skills mainly through peer coaching as observed in our study. While there were prior studies on isolated activities to improve students' individual skills (e.g., see Graham, 2006), our design synergises the skills in a bottom-up writing process that is directly situated in the context of essay writing. It should give the students a better sense of the relationships between individual skills and their writing.

Backed by the empirical findings of the pilot study, we compare the writing skills that the standard process writing and V.S.P.O.W. attempt to address, as depicted in Table 4 .

Table 4: Comparison of the writing skills addressed by the standard process writing and V.S.P.O.W.

\begin{tabular}{|l|l|l|}
\hline \multicolumn{1}{|c|}{ Skills } & \multicolumn{1}{|c|}{ "Standard" process writing } & \multicolumn{1}{c|}{ V.S.P.O.W. } \\
\hline $\begin{array}{l}\text { Vocabulary } \\
\text { (words/phrases) }\end{array}$ & $\begin{array}{l}\text { Addressed mostly through post- } \\
\text { drafting peer reviews; More for } \\
\text { correcting surface errors and } \\
\text { proposing alternative contents in } \\
\text { the drafts but perhaps less } \\
\text { effective in building up the } \\
\text { micro-skills in general. }\end{array}$ & $\begin{array}{l}\text { Greater emphasis in building up the } \\
\text { respective micro-skills through the first } \\
\text { four stages of the process. }\end{array}$ \\
\hline $\begin{array}{l}\text { Paragraph writing } \\
\text { (outlining) }\end{array}$ & $\begin{array}{l}\text { Perhaps irrelevant. } \\
\text { Might be generated individually } \\
\text { er collaboratively; Greater } \\
\text { emphasis on personal voices. }\end{array}$ & $\begin{array}{l}\text { Emphasis on richer expression of the } \\
\text { "standard content", i.e., the picture(s). }\end{array}$ \\
\hline Observation & $\begin{array}{l}\text { Usually emphasised; Could take } \\
\text { place during or after one } \\
\text { finished drafting. }\end{array}$ & $\begin{array}{l}\text { Not emphasised; some students might } \\
\text { take the initiative to review the words, } \\
\text { sentences or paragraphs generated by } \\
\text { their own groups on wiki. }\end{array}$ \\
\hline Self review & $\begin{array}{l}\text { Usually emphasised; Usually } \\
\text { taking place after one finished } \\
\text { drafting. }\end{array}$ & $\begin{array}{l}\text { Taking place during the collaborative } \\
\text { word/phrase pooling \& collaborative } \\
\text { sentence making. }\end{array}$ \\
\hline Peer review & $\begin{array}{l}\text { Emphasis in building up the } \\
\text { process writing skill. }\end{array}$ & $\begin{array}{l}\text { The bottom-up writing process is merely a } \\
\text { means and may be discarded when the } \\
\text { students return to individual writing. }\end{array}$ \\
\hline Writing process
\end{tabular}




\section{The adaptability of V.S.P.O.W.}

The V.S.P.O.W. process is highly customisable as demonstrated by the teacher in adapting the process in various rounds. Nevertheless, the student groups did not exercise customisation of the process by, for example, skipping intermediate steps. The teacher did not advise them to do so because she felt that they were new to the writing process and they worked in heterogeneous groups. Nevertheless, the teacher recognised the potential of empowering the students, perhaps in the student group level, in adapting their writing processes in individual rounds.

However, according to our findings from the post-interviews, some students might have exercised another form of adaptation at the essay writing stage. The "data" that were collaboratively generated during the first four stages would become rich resources to aid the students in this final stage. Such student-generated resources would create a sense of ownership to the students. Nonetheless, students could decide for themselves whether or not they would adopt the outlines (essay structure) generated by their own group, which group generated paragraphs to adopt, to what extent they wanted to make changes to the paragraphs, how to link the paragraphs together, or even re-write the entire essay from scratch. Some students might rely more on the group generated paragraphs and make little changes to them; others might instead leverage more on the group generated sentences and/or words/phrases, and so on. Such flexibility may have further positive implication on the writing process in the context of individual differences - which can be associated with two of the three human needs described by self-determination theory, "competence" and "autonomy", and Krashen's (1985) "input + 1" approach (except that "input + 1" can be determined by individual students, not the teacher).

\section{Issues in ICT mediation for V.S.P.O.W.}

Another significant characteristic of V.S.P.O.W. is the peer coaching within student groups during the face to face sessions. In questioning the dominance of 1:1 paradigm in computer-supported collaborative learning, Scott, Mandryk and Inkpen (2003) recommended concurrent, face to face, perhaps turn-taking, multi-user interaction that is supported by a shared physical computer display. Such a setting would lead to equal participations and increased enjoyment in the activity. Lin, Wong and Shao's (in press) study on comparing $1: 1$ and 1:m (one computer to many students) technologyenhanced learning settings resulted in a similar conclusion. Furthermore, Weissberg (2006) argued that second language writing is best acquired through a dialogic classroom model, as "social interaction provides an ideal context for mastering complex cognitive skills like writing" (p.3).

Likewise, we did not insist on 1:1 setting in the study and instead recommended blending it with one to many, face to face interactions, and turn-taking within a group. Our study has shown that during the face to face sessions, students in each particular group self-initiated peer coaching to support and complement each others' effort in carrying out their pre-writing tasks. Peer coaching also took place beyond the face to face sessions where most of the students repeatedly logged on to the wiki pages from home to review the contributions of their own and other groups. The aforementioned argument of the human need of "relatedness" (the willingness of offering peer coaching as a result of the sense of belonging) as described by self-determination theory, may explain this phenomenon. 
The process and the outcomes of such spontaneous interactions also seem to echo Collins' (1997) argument that "learning difficulties reflect differences, not deficiencies." (p.3), and Wong, Chin, Tan and Liu's (2010) advocacy of making errors work for the students and not against them. Students were more motivated to help each other when they worked in groups; and they felt less threatened when they made mistakes, as their group mates who "came in to rescue" might have their own weaknesses after all. Consequently, they achieved improvements in their weaker skills as well as gained pride through helping others in the skills they were good at. With such a social learning mechanism, it is hoped that the phenomenon of role differentiation will be gradually faded out as all students will overcome their respective weaknesses (i.e., the reduction of differences and learning difficulties) and therefore could contribute to the collaborative writing process equally. Indeed, despite being teacher-facilitated, the writing process of V.S.P.O.W. is ultimately placing the students at the centre - which does not mean that students are the centre of attention of teachers, but rather the centre of production of knowledge that occurs in various learning contexts (Layte \& Ravet, 2006; Wong, in-press).

In addition, the above-stated drawbacks of using a wiki for learning, as argued by other scholars (e.g., De Pedro et al., 2006; Wheeler \& Wheeler, 2007; Cole, 2009; Zorko, 2009), did not occur prominently in our study. One major difference between V.S.P.O.W. and most of other wiki based learning approaches is that in our approach, the wiki was employed as a tool for supporting the generation of intermediate products (vocabularies, sentences and paragraphs) of the students' writing process; while the rest have mostly made used of a wiki to facilitate students' co-creation of their final products (e.g., student reports) from the beginning. Therefore, our students were in general not reluctant to allow others to see their evolving group work on wiki or to revise each others' work. They were also highly motivated to participate in the learning process.

The only exception was that we observed similar situations as reported by Wheeler et al. (2008), that students tended to contribute more intensively to the wiki documents in class, but less so at home. Unlike in Wheeler, Yeomans and Wheeler's (2008) study where the college students usually only read the wiki pages that they had contributed to, our students had been keen on checking out, correcting errors in, commenting on and learning from other groups' work. This is the part where the Web 2.0 affordances of (asynchronous) interactivity and collaborative support had been put to use. Indeed, our work had confirmed Cole's (2009) argument that students need to be motivated by properly designed learning formats, which (we argued that) was what we had achieved.

\section{Conclusion and future work}

Teaching younger L2 students in writing, which involves the most complex and cognitively demanding linguistic skills, has always been a great challenge to language teachers and researchers. In addressing such a challenge, we collaborated with teachers to develop a wiki based collaborative writing approach. Our findings imply that the approach (1) would result in improvement of students' micro-skills for and motivation in writing, mainly through peer coaching; (2) is highly adaptable either by the teachers (i.e., differentiated instruction through customisation of the writing process) or the students themselves (i.e., autonomous learning - choice of how to make use of the group generated resources for their own writing) to suit the writing proficiency levels of individual student groups; (3) would turn the students' individual 
differences in the proficiency levels of various micro-skills from a (perceived) instructional challenge to an advantage in motivating effective peer coaching.

Seeing the effectiveness of the approach, Nan Chiau Primary School, our project partner, has translated it into a school-based curriculum for the entire Primary 4 level since 2010, and urged us to assist them in studying the feasibility of longitudinal implementation of the curriculum from Primary 2 to Primary 5 (2nd-5th grades), for both Chinese and English classes. In addition, several other Singapore and Taiwanese K-12 schools have been conducting or are planning for action research to experiment on different variations of the customisable approach to address their local needs (Wong, Sung, Lin \& Lin, in press).

Guided by the design research methodology, our next round of study that took place in February-July 2009 involved a different Primary 4 class to carry out four fresh rounds of V.S.P.O.W. activities. The new study focused more on the computersupported collaborative learning aspect of the face to face collaborations, where we deployed screen activity capturing software to record the collaborations in the student groups. The coding and analysis of this set of data is still ongoing, with the aim of revealing the group dynamics in the collaborative writing and peer coaching processes. We hope that this effort will help us in uncovering the relationship between the students' peer coaching activities and the changes in their writing skills.

Future design research cycles on the approach will instead focus on experimenting with more variations of the approach and to close the gaps in our current research design (such as the small sample size). There are two variations of the approach that we have identified for our future study, namely,

- Experiment with the application of reduced versions of the process, e.g., V.S. and V.S.P., to lower primary school students.

- Engage another class to experiment on intra-group synchronous pre-writing in 1:1. This is to examine and compare its group dynamics with the current 1:m setting.

In addition, Tee and Lee (2011) introduce an innovative model of encouraging teachers' design of technological pedagogical content knowledge (TPCK). Using technology to mediate students' learning difficulties is in essence a knowledge creation process and Tee and Lee's model could help to facilitate teachers' socialisation, externalisation, combination and internalisation processes. This is a possible model that we can employ for our future work with teachers.

\section{Acknowledgment}

This project was funded by the Learning Sciences Laboratory, National Institute of Education, Nanyang Technological University, Singapore (project ID: R8019.735. CW13). Special thanks go to Tze-Min Chung and the teachers of Nan Chiau Primary School for their contributions to the study.

\section{References}

Alm, A. (2006). CALL for autonomy, competence and relatedness: Motivating language learning environments in Web 2.0. The JALT CALL Journal, 2(3), 29-38. http:/ / www.jaltcall.org/journal/articles /2_3_Alm.pdf 
Alm-Lequeux, A. (2004). CALL IT motivation: On competence, relatedness and autonomy in computer-assisted language learning environments. In G. Wigglesworth (Ed.), Proceedings of the Marking Our Difference Conference (pp. 157-170). University of Melbourne. ISBN 0734030576 .

Atkinson, D. (2003). L2 writing in the post-process era: Introduction. Second Language Learning, 12(1), 3-15. http: / / dx.doi.org/10.1016/S1060-3743(02)00123-6

Batliwala, S. (2003). Bridging divides for social change: Practice-research interactions in South Asia. Organization, 10(3), 595-615. http:/ / dx.doi.org/10.1177/13505084030103019

Bradley, L., Lindström, B., \& Rystedt, H. (2010). Rationalities of collaboration for language learning in a wiki. ReCALL, 22(2), 247-265. http:/ / dx.doi.org/10.1017/S0958344010000108

Bray, J. N. (2002). Uniting teacher learning: Collaborative inquiry for professional development. New Directions for Adult and Continuing Education, 2002(94), 83-92. http: / / dx.doi.org/10.1002/ ace.62

Brown, A. L. (1992). Design experiments: Theoretical and methodological challenges in creating complex interventions in classroom settings. The Journal of the Learning Sciences, 2(2), 141-178. [abstract only] http: / / www.cc.gatech.edu/lst/jls/vol2no2.html\#Article1

Chetty, G. (2006). An investigation into the use of wikis for collaborative writing in L2 academic writing workshops: A pilot study. Unpublished Masters thesis, Edinburgh, UK: University of Edinburgh. http: / / hdl.handle.net/1842/ 2069

Cole, M. (2009). Using wiki technology to support student engagement: Lessons from the trenches. Computers $\mathcal{E}$ Education, 52(1), 141-146. http: / / dx.doi.org/10.1016/j.compedu.2008.07.003

Collins, J. L. (1997). Strategies for struggling writers. New York, NY: Guilford Press.

Darling-Hammond, L. (1996). The quiet revolution: Rethinking teacher development. Educational Leadership, 53(6), 4-10. http: / / www.ascd.org/publications/educational-leadership/mar96/ vol53/num06/The-Quiet-Revolution@-Rethinking-Teacher-Development.aspx

De Pedro, X., Rieradevall, M., López, P., Sant, D., Piñol, J., Núñez, L. \& Llobera, M. (2006). Writing documents collaboratively in higher education (I): Qualitative results from a 2-year project study. Congreso Internacional de Docencia Universitaria e Innovación, Barcelona, Spain. [this URL is for part II; verified 14 Nov 2011] http:/ / uniwiki.ourproject.org/tikidownload_wiki_attachment.php?attId=98\&page=Uniwiki-Congressos

Ferris, D. \& Hedgecock, J. (Eds.) (1998). Teaching ESL composition: Purpose, process and practice. Mahwah, NJ: Lawrence Erlbaum.

Flower, L. S. \& Hayes, J. R. (1977). Problem-solving strategies and the writing process. College English, 39(4), 449-461. http:/ / www.jstor.org/pss/375768

Flower, L. S. (1979). Writer-based prose: A cognitive basis for problems in writing. College English, 41(1), 19-37. http: / / www.jstor.org/pss /376357

Franklin, T., \& Van Harmelen, M. (2007). Web 2.0 for content for learning and teaching in higher education. Bristol: JISC. http: / / www.jisc.ac.uk/ publications / reports / 2007/ web2andpolicyreport.aspx

Godwin-Jones, R. (2003). Emerging technologies, blogs, and wikis: Environments for online collaboration. Language Learning \& Technology, 7(2), 12-16. http: / /lt.msu.edu/vol7num2/emerging/default.html 
Grabe, W. (2003). Reading and writing relations: Second language perspectives on research and practice. In B. Kroll (Ed.), Explore the dynamics of second language writing (pp. 242-262). New York, NY: Cambridge University Press.

Graham, S. (2006). Writing. In P. A. Alexander \& P. H. Winne (Eds.), Handbook of educational psychology (2nd ed.). (pp. 457-478). Mahwah, NJ: Lawrence Erlbaum.

He, J. (2005), Applying post-process theory in university EFL writing classes in China. Working Papers in Composition E TESOL, 1(1), 25-40. http: / / www.english.iup.edu/wpc\%26t/issues.htm/vol1issi/i1v12005.html/he.pdf

Hinkel, E. (2006). Current perspectives on teaching the four skills. TESOL Quarterly, 40(1), 109131. http:/ / www.ingentaconnect.com/ content/tesol/tq/2006/00000040/00000001/art00006

Holec, H. (1981). Autonomy and foreign language learning. Oxford: Pergamon.

Kessler, G. (2009). Student-initiated attention to form in wiki-based collaborative writing. Language Learning \& Technology, 13(1), 79-95. http:/ / llt.msu.edu/vol13num1/ kessler.pdf

Krashen, S. (1985). The input hypothesis: Issues and implications. London: Longman.

Layte, M. \& Ravet, S. (2006). Rethinking quality for building a learning society. In U.-D. Ehlers \& J. M. Pawlowski (Eds.), Handbook on quality and standardisation in e-learning (pp. 347-365). Berlin/Heidelberg: Springer.

Liang, R. J. (2000), The relationship between Singapore students' Chinese vocabulary and reading ability with their attitudes and Chinese learning achievement, In H. G. Zhang (Ed.), New trends in teaching Chinese (pp. 38-52), Hong Kong, ILEC.

Lin, C.-P., Wong, L-.H. \& Shao, Y.-J. (in-press). Comparison of 1:1 and 1:m CSCL environment for collaborative concept mapping. Journal of Computer Assisted Learning. http:/ / dx.doi.org/10.1111/j.1365-2729.2011.00421.x

Mak, B. \& Coniam, D. (2008). Using wikis to enhance and develop writing skills among secondary school students in Hong Kong. System, 36, 437-455. http: / / dx.doi.org/10.1016/j.system.2008.02.004

Matsuda, P. K. (2003). Process and post-process: A discursive history. Journal of Second Language Writing, 12(1), 65-83. http:/ / dx.doi.org/10.1016/S1060-3743(02)00127-3

Millard, D. E. \& Ross, M. (2006). Web 2.0: Hypertext by any other name? Proceedings of the 7th Conference on Hypertext $\mathcal{E}$ Hypermedia (pp.27-30), Odense, Denmark. http: / / eprints.ecs.soton.ac.uk/13085/

Murray, L. \& Hourigan, T. (2008). Blogs for specific purposes: Expressivist or socio-cognitivist approach? ReCALL, 20(1), 82-97. http:/ / dx.doi.org/10.1017/S0958344008000719

NDE (Nebraska Department of Education) (n.d.). Glossary - General (P-T). [not found 14 Nov 2011] http: / / www.nde.state.ne.us / READ / FRAMEWORK/glossary/general_p-t.html

People's Daily Online (2005, July 13). Singapore to pilot new Chinese language curriculum. [verified 14 Nov 2011]

http: / / english.peopledaily.com.cn/200507/13/eng20050713_195782.html

Scott, S. D., Mandryk, R. L. \& Inkpen, K. M. (2003). Understanding children's collaborative interactions in shared environments. Journal of Computer Assisted Learning, 19(2), 220-228. http: / / dx.doi.org/10.1046/j.0266-4909.2003.00022.x 
Silva, T. (1990). A comparative study of the composing of selected ESL and native English speaking freshman writers. Dissertation Abstracts International, 51(10), 3397A.

Silva, T. (1993). Toward an understanding of the distinct nature of L2 writing: The ESL research and its implications. TESOL Quarterly, 27(4), 657-677. http:/ / www.jstor.org/stable/3587400

Sim, S. H. (2005). Teaching Chinese composition in Singapore secondary school. In M. S. Shum \& D. L. Zhang (Eds.), Teaching writing in Chinese speaking areas (pp.245-258), Springer Netherlands.

Tee, M. Y. \& Lee, S. S. (2011). From socialisation to internalisation: Cultivating technological pedagogical content knowledge through problem-based learning. Australasian Journal of Educational Technology, 27(1), 89-104. http:/ / www.ascilite.org.au/ajet/ajet27/ tee.html

Vygotsky, L.S. (1978). Mind in society: The development of higher psychological processes. Cambridge: Harvard University Press.

Weissberg, R. (2006). Connecting speaking $\mathcal{E}$ writing in second language writing instruction. Ann Arbor: University of Michigan Press.

Wheeler S. \& Wheeler D. (2007). Evaluating wiki as a tool to promote quality academic writing skills. Conference ICL 2007. [verified 14 Nov 2011] http:/ / telearn.noekaleidoscope.org/warehouse/158_Final_Paper_(001680v1).pdf

Wheeler S., Yeomans P. \& Wheeler D. (2008). The good, the bad and the wiki: Evaluating student generated content for collaborative learning. British Journal of Educational Technology, 39(6), 987-995. http: / dx.doi.org/10.1111/j.1467-8535.2007.00799.x

Williams, J. (2005). Teaching writing in second and foreign language classrooms. New York: McGraw Hill.

Wong, L.-H. (in press). A learner-centric view of mobile seamless learning. British Journal of Educational Technology.

Wong, L.-H., Boticki, I., Sun, J. \& Looi, C.-K. (2011). Improving the scaffolds of a mobile-assisted Chinese character forming game via a design-based research cycle. Computers in Human Behavior, 27(5), 1783-1793. http:/ / dx.doi.org/10.1016/j.chb.2011.03.005

Wong, L.-H., Chai, C.-S. \& Gao, P. (2011). The Chinese input challenges for Chinese as second language learners in computer mediated writing: An exploratory study. The Turkish Online Journal of Educational Technology, 10(3), 233-248. http: / / www.tojet.net/articles/10327.pdf

Wong, L.-H., Chin, C.-K., Tan, C.-L. \& Liu, M. (2010). Students' personal and social meaning making in a Chinese idiom mobile learning environment. Educational Technology \& Society, 13(4), 15-26. http:/ / www.ifets.info/journals / 13_4/3.pdf

Wong, L.-H., Gao, P., Chai, C.-S. \& Chin, C.-K. (2011). Where research, practice and the authority meet: A collaborative inquiry for development of technology-enhanced Chinese language curricula. The Turkish Online Journal of Educational Technology, 10(1), 232-243. http: / / www.tojet.net/ articles / 10124.pdf

Wong, L.-H., Sung, Y.-L., Lin, C.-P., \& Lin. C.-C. (in-press). Group Scribbles to support elementary students' writing based on VSPOW model: A preliminary study. Proceedings of International Conference on Computers in Education 2011. Chiang Mai, Thailand.

Yau, M. (1989). A quantitative comparison of L1 and L2 writing processes. Paper presented at the 23rd Annual TESOL Convention, San Antonio, Texas. 
Zorko, V. (2009). Factors affecting the way students collaborate in a wiki for English language learning. Australasian Journal of Educational Technology, 25(5), 645-665.

http:/ / www.ascilite.org.au/ajet/ajet25/zorko.html

Authors: Dr Lung-Hsiang Wong, Dr Wenli Chen, Dr Ching-Sing Chai

National Institute of Education, Nanyang Technological University, Singapore

Email: lunghsiang.wong@nie.edu.sg, wenli.chen@nie.edu.sg,

chingsing.chai@nie.edu.sg

Web: http: / / www.nie.edu.sg/learning-sciences-and-technologies/about-lst

Chee-Kuen Chin, Singapore Centre for Chinese Language.

Email: cheekuen.chin@sccl.sg Web: http:/ / en.sccl.sg/

Dr Ping Gao, University of Northern Iowa. Email: ping.gao@uni.edu

Web: http: / / www.uni.edu/coe/ departments/ curriculum-instruction/faculty-and-

staff/ping-gao

Please cite as: Wong, L.-H., Chen, W., Chai, C.-S., Chin, C.-K. \& Gao, P. (2011). A

blended collaborative writing approach for Chinese L2 primary school students.

Australasian Journal of Educational Technology, 27(7), 1208-1226.

http: / / www.ascilite.org.au/ajet/ajet27/ wong.html 